\title{
Media Standardization for Hydroponic Culture to Screen Wheat Genotypes for Nitrogen Use Efficiency
}

\author{
K.M. Ranjitha ${ }^{1}$, Suma S. Biradar ${ }^{2 *}$, S.A. Desai ${ }^{2 *}$, V. Rudra Naik², \\ Sumangala Bhat ${ }^{1}$, T.N. Satisha ${ }^{2}$, Guruprasad Hiremath ${ }^{2}$, \\ K.J. Yashawantha Kumar' ${ }^{2}$ C.K. Chethana ${ }^{2}$ and K. Venkatesh ${ }^{3}$ \\ ${ }^{1}$ Department of Biotechnology, University of Agricultural Sciences, \\ Dharwad 580 005, Karnataka, India \\ ${ }^{2}$ AICRP on Wheat, MARS, University of Agricultural Sciences, Dharwad 580005 , \\ Karnataka, India \\ ${ }^{3}$ Indian Institute of Wheat and Barley Research, Karnal, Haryana, India \\ *Corresponding author
}

\section{A B S T R A C T}

\begin{tabular}{|l}
\hline Ke y w o r d s \\
NUE, Hydroponics, \\
Hogland solution, \\
Variability and \\
Genotype $\times$ \\
Nitrogen \\
interaction. \\
\hline Article Info \\
\hline Accepted: \\
19 October 2017 \\
Available Online: \\
10 December 2017
\end{tabular}

Root architecture is critical for efficient nutrient acquisition. This necessitates the investigations on plant root system to identify genotype with high nitrogen uptake efficiency under target environment. A hydroponic culture was employed to standardize the media to be used for screening of wheat genotypes for Nitrogen Use Efficiency (NUE) using proven low nitrogen susceptible and tolerant genotypes. Four different modified Hoagland solutions $\left(\mathrm{NH}_{4} \mathrm{NO}_{3}\right.$ media, $\mathrm{NO}_{3}$ complete, $\mathrm{NO}_{3}$ half, and $\mathrm{N}$ minus media) were used and five wheat genotypes namely, UASBW 11328, GW 322 and PDW 291, NARBADA 4 and C 306 were grown in hydroponic culture for 30 days. Results regarding analysis of variance for interactions of genotypes and nitrogen levels revealed that all the genotypes exhibited the significant difference among themselves for all the four different solutions. Over the different media, low N susceptible genotype C 306 exhibited significant difference for most of the traits. While over the genotypes, both half $\mathrm{NO}_{3}$ and $\mathrm{N}$-minus recorded significant difference for root and shoot traits. Thus it was concluded that, half $\mathrm{NO}_{3}$ medium is the best to screen the wheat genotypes for screening for NUE under 50 per cent supply. Further, this method gives the way for quick initial screening of wheat genotypes for NUE.

\section{Introduction}

Wheat (Triticum aestivum L.) is the main staple food of the world population and second important staple food crop in the country. Most of the agricultural crops, including wheat, are inefficient at uptaking and utilizing applied nitrogen fertilizer (Hitz, 2015). This emphasises breeding of wheat cultivars with improved nitrogen use efficiency for reducing excessive input of fertilizers along with maintaining an acceptable yield. Plant roots play important role in nutrient uptake and selection for traits related to root architecture are of great importance for yield performance of crop species however, they remain poorly understood (Petrarulo et al., 2015). Study of 
factors affecting the uptake of nutrients by roots and mechanism of element uptake in the field can be technically difficult (Hirel et al., 2007). However, hydroponically grown plants, which facilitate rapid access to the root system where both physiology and molecular techniques could be, applied together (Garnet et al., 2009). Cultivation of plant in mineral nutrient solution rather than in soil allows us to study the relationship between plant root nutritional uptake mechanism and plant growth (An et al., 2006). Hence, An et al., (2006) studied the effect of $\mathrm{N}$ levels on early growth of wheat seedlings using hydroponic culture. Keeping these points in view, the present investigation was conducted by supplying different forms and levels of $\mathrm{N}$ to Hogland medium using the proven genotypes for NUE, by studying the effect of $\mathrm{N}$ levels on the growth and development of wheat shoot and root architecture.

\section{Materials and Methods}

To explore the objectives outlined above a hydroponic experiment was carried out in the Department of Biotechnology, University of Agricultural Sciences, Dharwad. Five diverse wheat genotypes namely UASBW 11328, GW 322, PDW 291, NARBADA 4 and C 306 were selected on the basis of their yield potential and NUE component traits like harvest index, NUE etc. falling in category such as high (UASBW 11328 and GW 322), medium (PDW 291 and NARBADA 4) and low (C 306) NUE genotypes (Satisha, 2016). The genotype UASBW 11328 is high yielding, having maximum biomass and high NUE. GW 322 is having high grain yield, high nitrogen uptake and utilization efficiency coupled with high harvest index and protein content under 50 per cent N. PDW 291 and NARBADA 4 are with high grain protein content and moderate NUE. The genotype C 306 is the tallest genotype, low chlorophyll content during grain filling stage, low grain yield, harvest index, nitrogen harvest index (NHI) and NUE under normal N condition.

The experiment was conducted in hydroponic culture with modified Hoagland medium. The media was standardized for the hydroponic culture to screen the genotypes for nitrogen use efficiency in bread wheat. Four different modified Hoagland solutions were used viz., media with both ammonical and nitrate form of $\mathrm{N}\left(\mathrm{NH}_{4} \mathrm{NO}_{3}\right.$ media), $\mathrm{NO}_{3}$ complete media, $\mathrm{NO}_{3}$ half media, and $\mathrm{N}$ minus media wherein in the $\mathrm{N}$ minus media, remaining micro nutrients and iron sources used was same as that of standard Hoagland solution (Hoagland and Arnon, 1938). The compositions of all four media are given in the Table 1, 2 and 3. Five genotypes were grown on the four different medium. Uniform seeds of five genotypes were surface-sterilised in 70 per cent ethanol for $1 \mathrm{~min}$, followed by three rinses with deionised water. The seeds were germinated on filter paper in petri plates at room temperature over two days. The seedlings, with the embryogenic primary root, the two pairs of secondary roots (seminal roots) and the coleoptile (1-2 cm long) were then transplanted into supported hydroponic system with two replications. This system was formed using a polystyrene thermocol substrate that was placed into thermocol tanks that was filled with four different nutrient solutions (Hoagland modified solution) (An et al., 2006; Petrarulo et al., 2015). The nutrient solution in the tanks was renewed every 4-5 days and $\mathrm{pH}$ of the solution was adjusted to 6.0 using diluted $\mathrm{NaOH}$ and $\mathrm{HCl}$ before refreshing and maintained at the temperature of $25 \pm 2^{0} \mathrm{C}$ with 75 per cent relative humidity and photoperiod of 16/8 hours. Four weeks after transplanting, the plant along with entire root system was carefully removed from the trays with the thermocol sheet. Data was collected on chlorophyll content, root length, shoot length, root to shoot ratio, number of primary roots, number of leaves, root fresh 
and dry weight, shoot fresh and dry weight. After observations, the aerial parts of plants and roots were separated and oven dried for 48 hours at $80{ }^{\circ} \mathrm{C}$ and finally recorded the shoot dry weight (SDW) and root dry weight (RDW) (Petrarulo et al., 2015).

\section{Results and Discussion}

\section{Analysis of variance for factorial CRD analysis}

The mean sum of squares for root and shoot traits under four nitrogen levels viz., $\mathrm{NH}_{4} \mathrm{NO}_{3}$, $\mathrm{NO}_{3}$ complete, $\mathrm{NO}_{3}$ half and $\mathrm{N}$ minus media for five genotypes are presented in Table 4.

Analysis of variance showed significant variation among five genotypes at four different levels of nitrogen for root and shoot traits. This indicated existence of differences among genotypes at different levels of $\mathrm{N}$. The significant genotype $\times$ nitrogen level interaction was observed for most of the traits except for the traits like, number of leaves and dry weight of root. This indicated considerable amount of variability present in the material.

Effect of different nitrogen levels on five bread wheat genotypes grown under hydroponic culture

Data obtained from the analysis of interaction between genotypes and different nitrogen levels revealed the existence of sufficient genetic variability among the genotypes. In general, over the different nitrogen levels, the low N susceptible genotype C 306 exhibited significant differences with respect to mean performance of the root and shoot traits (Table 5 and Fig. 1). C 306 genotype which was bred for drought tolerance having good root parameters however, susceptible to low N supply (Renu Munjal and Satyavir Singh Dhanda, 2016). This suggests that root parameters alone may not contribute to NUE however it requires efficient nitrogen uptake and high harvest index.

Table.1 Components for Media with both ammonical and nitrate form of $\mathrm{N}$ used for hydroponic study

\begin{tabular}{|l|l|c|}
\hline Sl. No. & Composition & For 1 litre (ml) \\
\hline 1 & Calcium dihydrogen phosphate & 10 \\
\hline 2 & Calcium sulphate & 2 \\
\hline 3 & Potassium sulphate & 5 \\
\hline 4 & $\mathrm{MgSO}_{4}$ & 2 \\
\hline 5 & $\mathrm{NH}_{3} \mathrm{NO}_{4}$ & 1 \\
\hline 6 & $\mathrm{Micronutrients}^{\mathbf{- 1}}$ \\
\hline \multirow{5}{*}{} & $\mathrm{H}_{3} \mathrm{BO}_{3}$ & 2.86 \\
\cline { 2 - 3 } & $\mathrm{ZnSO}_{4}$ & 0.22 \\
\cline { 2 - 3 } & $\mathrm{CuSO}_{4}$ & 0.051 \\
\cline { 2 - 3 } & $\mathrm{MnCl}_{2}$ & 1.81 \\
\cline { 2 - 3 } & $\mathrm{H}_{2} \mathrm{MoO}_{4}, \mathrm{H}_{2} \mathrm{O}$ & 0.09 \\
\hline 7 & $\mathrm{Iron} \mathrm{EDTA}^{2}$ & 1.5 \\
\hline
\end{tabular}


Table.2 Components for $\mathrm{NO}_{3}$ complete media and $\mathrm{NO}_{3}$ half media used for hydroponic study

\begin{tabular}{|l|l|c|c|}
\hline Sl. No. & Composition & $\begin{array}{c}\mathbf{N O}_{\mathbf{3}} \text { complete media } \\
\left(\mathbf{m l l}^{-\mathbf{1}}\right)\end{array}$ & $\begin{array}{c}\mathbf{N O}_{\mathbf{3}} \text { half media } \\
\left(\mathbf{m l l}^{\mathbf{- 1}}\right)\end{array}$ \\
\hline 1 & Potassium nitrate $(1 \mathrm{M})$ & $12.5 \mathrm{ml}$ & $6.25 \mathrm{ml}$ \\
\hline 2 & Calcium nitrate $(1 \mathrm{M})$ & $12.5 \mathrm{ml}$ & $6.25 \mathrm{ml}$ \\
\hline 3 & $\begin{array}{l}\text { Potassium dihydrogen } \\
\text { phosphate }(1 \mathrm{M})\end{array}$ & $2.5 \mathrm{ml}$ & $1.25 \mathrm{ml}$ \\
\hline 4 & $\mathrm{MgSO}_{4}(1 \mathrm{M})$ & $5 \mathrm{ml}$ & $2.5 \mathrm{ml}^{-1}$ \\
\hline 5 & $\mathbf{M i c r o n u t r i e n t s}^{-\mathbf{1}}$ & 2.43 \\
\hline \multirow{3}{*}{} & $\mathrm{H}_{3} \mathrm{BO}_{3}$ & 2.86 & 0.11 \\
\cline { 2 - 4 } & $\mathrm{ZnSO}_{4}$ & 0.22 & 0.026 \\
\cline { 2 - 4 } & $\mathrm{CuSO}_{4}$ & 0.051 & 0.95 \\
\cline { 2 - 4 } & $\mathrm{Mncl}_{2}$ & 1.81 & 0.045 \\
\cline { 2 - 4 } & $\mathrm{H}_{2} \mathrm{MoO}_{4}, \mathrm{H}_{2} \mathrm{O}$ & 0.09 & $1.87 \mathrm{ml}$ \\
\hline
\end{tabular}

Table.3 Components for $\mathrm{N}$ minus media used for hydroponic study

\begin{tabular}{|l|l|c|}
\hline Sl. No. & Composition & For 1 litre (ml) \\
\hline 1 & Calcium dihydrogen phosphate & 10 \\
\hline 2 & Calcium sulphate & 2 \\
\hline 3 & Potassium sulphate & 5 \\
\hline 4 & $\mathrm{MgSO}_{4}$ & 2 \\
\hline 5 & $\mathrm{Micronutrients}_{\mathbf{g l}}^{-\mathbf{1}}$ \\
\hline \multirow{5}{*}{} & $\mathrm{H}_{3} \mathrm{BO}_{3}$ & 2.86 \\
\cline { 2 - 3 } & $\mathrm{ZnSO}_{4}$ & 0.22 \\
\cline { 2 - 3 } & $\mathrm{CuSO}_{4}$ & 0.051 \\
\cline { 2 - 3 } & $\mathrm{Mncl}_{2}$ & 1.81 \\
\cline { 2 - 3 } & $\mathrm{H}_{2} \mathrm{MoO}_{4}, \mathrm{H}_{2} \mathrm{O}$ & 0.09 \\
\hline 6 & Iron EDTA & 1.5 \\
\hline
\end{tabular}

Table.4 Mean performance of the parents for root and shoot traits under half $\mathrm{NO}_{3}$ media in hydroponic culture

\begin{tabular}{|l|c|c|c|c|c|c|c|c|c|c|}
\hline \multicolumn{1}{|c|}{ Parents } & SPAD & RL & SL & RSR & NPR & NL & FWR & FWS & DWR & DWS \\
\hline GW 322 & 30.80 & 28.50 & 37.60 & 0.76 & 10.38 & 6.58 & 0.16 & 0.93 & 0.03 & 0.26 \\
\hline 2 WYCYT 34 & 30.05 & 30.71 & 40.53 & 0.76 & 11.91 & 6.00 & 0.17 & 0.97 & 0.04 & 0.22 \\
\hline K9107 & 28.65 & 29.82 & 39.30 & 0.76 & 11.25 & 5.90 & 0.17 & 0.86 & 0.04 & 0.19 \\
\hline UAS323 & 30.45 & 29.15 & 38.97 & 0.75 & 9.50 & 6.00 & 0.14 & 0.90 & 0.04 & 0.20 \\
\hline RAJ4248 & 28.95 & 28.05 & 37.52 & 0.75 & 10.53 & 6.00 & 0.13 & 0.86 & 0.03 & 0.18 \\
\hline C306 & 30.35 & 28.68 & 39.46 & 0.73 & 9.83 & 6.42 & 0.17 & 0.96 & 0.04 & 0.27 \\
\hline
\end{tabular}

$*$ and ** indicates significant at $5(\%)$ and $1(\%)$ level of significance, respectively.

SPAD $=$ Chlorophyll content, $\mathrm{RL}=$ Root length $(\mathrm{cm}), \mathrm{SL}=$ Shoot length $(\mathrm{cm}), \mathrm{RSR}=$ Root to shoot ratio, NPR $=$

Number of primary roots, NL $=$ Number of leaves, FWR $=$ Fresh weight of root $(\mathrm{g})$, FWS $=$ Fresh weight of shoot $(\mathrm{g})$, DWR $=$ Dry weight of root $(\mathrm{g})$, DWS $=$ Dry weight of shoot $(\mathrm{g})$. 
Table.5 Effect of different nitrogen levels on five bread wheat genotypes grown under hydroponic culture

\begin{tabular}{|c|c|c|c|c|c|c|c|c|c|c|c|}
\hline & Treatments & SPAD & $\mathbf{R L}$ & SL & RSR & NL & NPR & FWR & FWS & DWR & DWS \\
\hline \multirow{8}{*}{ Genotypes (G) } & G1 & $30.15^{* * *}$ & 35.85 & 33.65 & 1.15 & 5.35 & 7.22 & 0.08 & 0.78 & 0.03 & 0.12 \\
\hline & G2 & 27.74 & 33.67 & 32.84 & 1.20 ** & $5.89 * *$ & 9.03 & 0.06 & 0.69 & 0.03 & 0.12 \\
\hline & G3 & $29.73 * *$ & 36.62 & 33.06 & $1.18^{* * *}$ & 5.18 & 8.77 & 0.06 & 0.65 & 0.03 & 0.10 \\
\hline & G4 & 25.42 & $41.28 * *$ & $44.83 * *$ & 0.93 & 5.44 & 10.61 & 0.09 & $1.16^{* * *}$ & $0.05 * *$ & $0.16^{* * *}$ \\
\hline & G5 & 28.00 & $40.13 * *$ & $40.13 * *$ & 0.96 & $5.76 * *$ & $9.55^{* * *}$ & $0.10^{* * *}$ & 0.86 & $0.05 * *$ & $0.14^{* * *}$ \\
\hline & Mean & 28.21 & 37.51 & 36.90 & 1.09 & 5.52 & 9.04 & 0.08 & 0.83 & 0.04 & 0.13 \\
\hline & S.Em. \pm & 0.42 & 0.56 & 0.52 & 0.02 & 0.09 & 0.31 & 0.01 & 0.07 & 0.00 & 0.01 \\
\hline & C.D. (1\%) & 1.70 & 2.27 & 2.11 & 0.07 & 0.36 & 1.24 & 0.03 & 0.27 & 0.01 & 0.02 \\
\hline \multirow{7}{*}{ Nitrogen level (N) } & N1 & $36.12^{* * *}$ & 35.62 & $42.22 * *$ & 0.82 & 6.08 & 9.18 & 0.07 & 1.00 & 0.03 & 0.16 \\
\hline & $\mathrm{N} 2$ & 29.49 ** & 26.44 & 35.70 & 0.73 & 5.72 & 10.25 & 0.08 & 0.92 & 0.04 & 0.13 \\
\hline & N3 & 27.02 & 32.66 & $41.81 * *$ & 0.79 & $6.05 * *$ & $9.89 * *$ & $0.10 * *$ & $1.30 * *$ & $0.06^{* * *}$ & $0.18^{* * *}$ \\
\hline & N4 & 19.65 & $55.32 * *$ & 27.88 & 2.00 & 4.23 & 6.82 & 0.06 & 0.09 & 0.03 & 0.05 \\
\hline & Mean & 28.07 & 37.51 & 36.90 & 1.09 & 5.52 & 9.04 & 0.08 & 0.83 & 0.04 & 0.13 \\
\hline & S.Em. \pm & 0.38 & 0.50 & 0.47 & 0.02 & 0.08 & 0.28 & 0.01 & 0.06 & 0.00 & 0.01 \\
\hline & C.D. (1\%) & 1.52 & 2.03 & 1.89 & 0.06 & 0.32 & 1.11 & 0.02 & 0.24 & 0.01 & 0.02 \\
\hline \multirow{23}{*}{ Interaction $(\mathbf{G} \times \mathbf{N})$} & G1N1 & $37.95^{* *}$ & 40.36 & $39.17 * *$ & 1.02 & $5.92 * *$ & 7.25 & 0.05 & $1.02 * *$ & 0.02 & 0.17 ** \\
\hline & G1N2 & $31.70^{* * *}$ & 22.37 & 33.57 & 0.64 & 5.50 & 9.47 & 0.09 & $0.91 * *$ & 0.02 & 0.11 \\
\hline & G1N3 & $29.75^{\text {*** }}$ & 26.05 & 37.40 ** & 0.69 & $5.80 * *$ & 6.00 & 0.10 & $1.11^{* * *}$ & 0.05 & $0.16^{* * *}$ \\
\hline & G1N4 & 21.20 & 54.64 & 24.47 & $2.23 * *$ & 4.17 & 6.17 & 0.07 & 0.07 & 0.03 & 0.05 \\
\hline & G2N1 & $34.40 * *$ & 26.77 & 36.12 & 0.73 & $6.50 * *$ & 8.63 & 0.04 & 0.63 & 0.03 & 0.14 ** \\
\hline & G2N2 & $30.85^{* * *}$ & 29.08 & 32.21 & 0.92 & $6.43 * *$ & 10.00 *** & 0.08 & 0.83 & 0.04 & 0.13 \\
\hline & G2N3 & $28.75^{* * *}$ & 37.66 & $40.08 * *$ & 0.94 & $6.45 * *$ & $11.00 * *$ & 0.09 & $1.25^{* * *}$ & 0.05 & $0.19^{\text {*** }}$ \\
\hline & G2N4 & 16.95 & 41.16 & 22.97 & 2.22 & 4.17 & 6.50 & 0.03 & 0.07 & 0.04 & 0.04 \\
\hline & G3N1 & $39.03^{* *}$ & 34.08 & $39.75 * *$ & 0.90 & $6.00 * *$ & 8.45 & 0.05 & $0.98 * *$ & 0.02 & $0.17^{* *}$ \\
\hline & G3N2 & $29.45^{* * *}$ & 24.62 & 35.17 & 0.72 & 5.00 & 9.64 & 0.06 & 0.62 & 0.04 & 0.12 \\
\hline & G3N3 & $29.10^{\text {** }}$ & 28.10 & 33.50 & 0.87 & 5.55 & 9.67 & 0.08 & 0.91 & 0.04 & 0.10 \\
\hline & G3N4 & 21.35 & 59.68 & 23.83 & $2.24 * *$ & 4.17 & 7.33 & 0.07 & 0.09 & 0.03 & 0.04 \\
\hline & G4N1 & $32.90^{* *}$ & 40.32 & $53.73 * *$ & 0.75 & $6.00 * *$ & $11.30^{* *}$ & 0.10 & $1.42 * *$ & 0.03 & 0.17 ** \\
\hline & G4N2 & 27.25 & 30.22 & 36.02 & 0.70 & $5.75 * *$ & $12.17 * *$ & 0.12 & $1.23 * *$ & 0.06 & $0.18^{* * *}$ \\
\hline & G4N3 & 22.50 & 39.34 & $53.48 * *$ & 0.74 & 6.00 & $11.65^{* * *}$ & 0.11 & $1.89 * *$ & 0.08 & $0.24 * *$ \\
\hline & G4N4 & 16.25 & 55.26 & 36.10 & 1.55 & 4.00 & 7.33 & 0.05 & 0.11 & 0.04 & 0.06 \\
\hline & G5N1 & $36.30^{* * *}$ & 36.57 & $42.33 * *$ & 0.72 & $6.00 * *$ & $10.25^{* *}$ & 0.12 & $0.94 * *$ & 0.04 & $0.15^{* *}$ \\
\hline & G5N2 & $28.20^{* * *}$ & 25.94 & $41.52 * *$ & 0.64 & 5.91 & $10.00^{* * *}$ & 0.07 & $1.02 * *$ & 0.03 & $0.14^{* *}$ \\
\hline & G5N3 & 25.00 & 32.15 & $44.60^{* * *}$ & 0.73 & $6.45 * *$ & $11.15^{* * *}$ & 0.13 & $1.35^{* *}$ & 0.08 & $0.22^{* *}$ \\
\hline & G5N4 & 23.61 & $65.89^{* * *}$ & 32.06 & 1.76 & 4.67 & 6.80 & $0.09^{* * *}$ & 0.12 & $0.06^{* * *}$ & 0.07 \\
\hline & Mean & 28.12 & 37.51 & 36.90 & 1.09 & 5.52 & 9.04 & 0.08 & 0.83 & 0.04 & 0.13 \\
\hline & S.Em. \pm & 0.85 & 1.13 & 1.05 & 0.03 & 0.18 & 0.62 & 0.01 & 0.13 & 0.01 & 0.01 \\
\hline & C.D. (1\%) & 3.41 & 4.54 & 4.22 & 0.14 & 0.72 & 2.48 & 0.05 & 0.54 & 0.03 & 0.05 \\
\hline
\end{tabular}

$*$ and ** indicates significant at $5(\%)$ and $1(\%)$ level of significance, respectively.

Genotypes (G): G1- UAS BW 11328, G2 - GW 322, G3 - PDW291, G4 - NARBADA 4, G5 - C306. Nitrogen level (N) : N1- $\mathrm{NH}_{4} \mathrm{NO}_{3} \mathrm{media} \mathrm{N}_{2}-\mathrm{NO}_{3}$

complete, $\mathrm{N} 3-\mathrm{NO}_{3}$ half, $\mathrm{N} 4-\mathrm{N}$ minus. 
Fig.1 Phenotype with respect to root and shoot traits of different bread wheat genotypes under different nitrogen levels

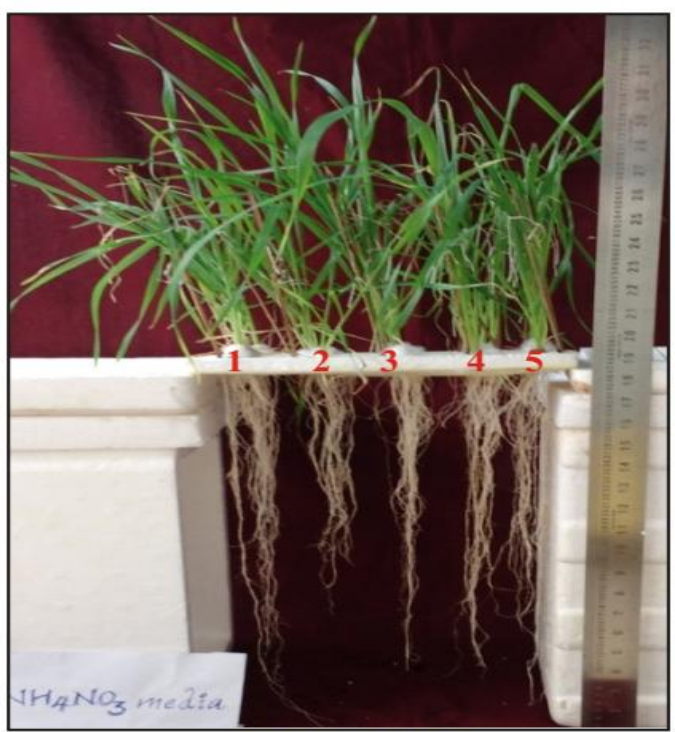

$\mathrm{NH}_{4} \mathrm{NO}_{3}$ Media

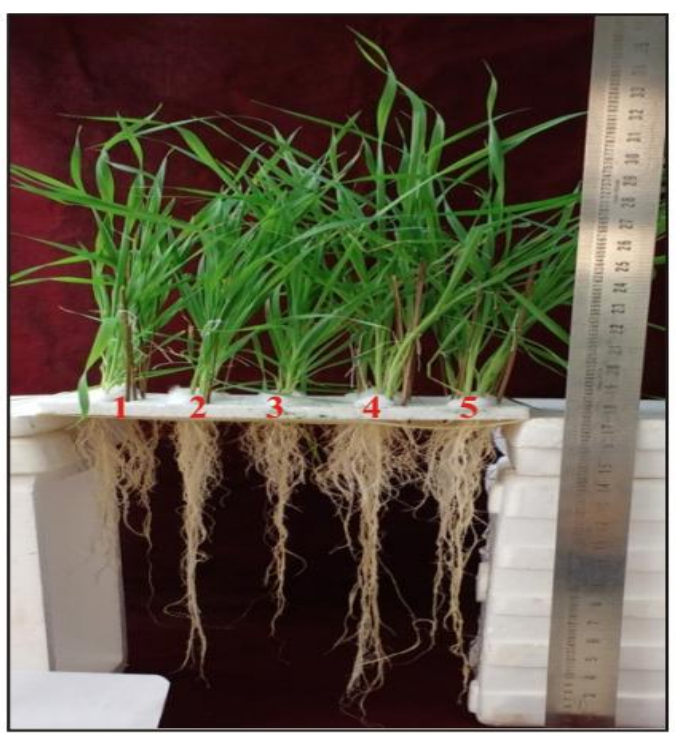

$\mathrm{NO}_{3}$ half media

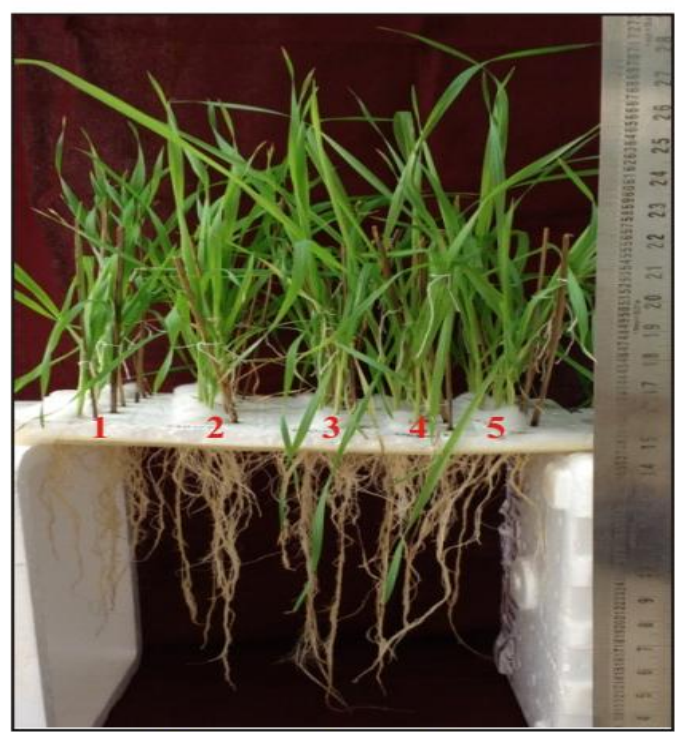

$\mathrm{NO}_{3}$ complete media

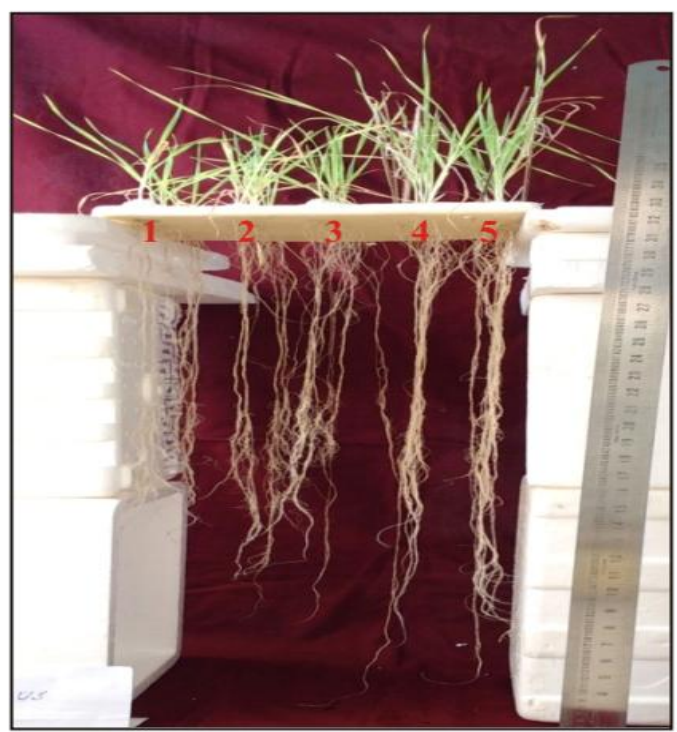

N minus media

1 - UASBW 11328; 2 - WH 1022; 3 - PDW 291; 4 - NARBADA 4; 5 - C 306

With respect to different nitrogen levels, $\mathrm{NO}_{3}$ half media exhibited significant differences from other nitrogen levels for the traits shoot length, number of primary roots, number of leaves, fresh weight and dry weight of root and fresh weight of shoot over the genotypes. The results regarding interactions of genotypes with nitrogen levels indicated that the low NUE genotype $\mathrm{C} 306$ at half $\mathrm{NO}_{3}$ recorded significant difference for most of the traits and further, low $\mathrm{N}$ susceptible and tolerant genotypes exhibited significant differences among themselves for root parameters suggesting suitability of this media for screening of wheat genotypes for NUE. 
Hydroponic system was proposed to screen the genotypes for nitrogen use efficiency by studying root and shoot traits. Results regarding analysis of variance for interactions of genotypes and nitrogen levels revealed that all the genotypes exhibit the significant difference among themselves for all the four different solutions and indicated that the low NUE genotype $\mathrm{C} 306$ at half $\mathrm{NO}_{3}$ medium recorded significant difference for most of the traits and further, it distinguished medium and high nitrogen use efficiency genotypes. Hence, the $\mathrm{NO}_{3}$ half media can be further utilized to screen genotypes for NUE that are competitive for nitrogen $(\mathrm{N})$ uptake in early vegetative stages of growth. Hence, the half $\mathrm{NO}_{3}$ medium was further used in the screening of fifteen single cross hybrids and parents for nitrogen use efficiency. The present study gives new method for quick initial screening of wheat genotypes for NUE based on root parameters.

\section{References}

An, D. G., Su, J. Y., Liu, Q. Y., Zhu, Y. G., Tong, Y. P., Li, J. M., Jing, R. L., Li, B. and Li, Z. S., 2006, Mapping QTLs for nitrogen uptake in relation to the early growth of wheat (Triticum aestivum L.). Plant Soil, 284: 73-84.

Garnett, T., Conn, V. and Kaiser, B. N., 2009, Root based approaches to improving nitrogen use efficiency in plants. Plant
Cell Environ., 32: 1272-1283.

Hirel, B., Le Gouis, J., Ney, B. and Gallais, A., 2007, The challenge of improving nitrogen use efficiency in crop plants: towards a more central role for genetic variability and quantitative genetics within integrated approaches. J. Exp. Bot., 58: 2369-2387.

Hitz Katlyn, 2015, Breeding for nitrogen use efficiency in soft red winter wheat. M.Sc., (Agri.) Thesis, Univ. of Kentucky, Lexington (United states).

Hoagland, D. R. and Arnon, D. I., 1950, The water culture method for growing plants without soil. California Agr. Expt. Sta. Circ. p. 347.

Petrarulo, M., Marone, D., Ferragonio, P., Cattivelli, L., Rubiales, D., De Vita, P. and Mastrangelo, A. M., 2015, Genetic analysis of root morphological traits in wheat. Mol. Genet. Genomics, 290: 785-806.

Renu Munjal and Satyavir Singh Dhanda, 2016, Assessment of Drought Resistance in Indian Wheat Cultivars for Morpho-Physiological Traits. Journal of Crop Breeding and Genetics 2(1): 74-81.

Sathisha, T. N., 2016, Genetic analysis and molecular characterization of wheat genotypes for nitrogen use efficiency Ph. D., (Agri.) Thesis, Univ. Agric. Sci., Dharwad, Karnataka (India).

\section{How to cite this article:}

Ranjitha, K.M., Suma S. Biradar, S.A. Desai, V. Rudra Naik, Sumangala Bhat, T.N. Satisha, Guruprasad Hiremath, K.J. Yashawantha Kumar, C.K. Chethana and Venkatesh, K. 2017. Media Standardization for Hydroponic Culture to Screen Wheat Genotypes for Nitrogen Use Efficiency. Int.J.Curr.Microbiol.App.Sci. 6(12): 2814-2820.

doi: https://doi.org/10.20546/ijcmas.2017.612.327 